\title{
Retraction Note: Comparison of Mechanical Properties and Sensitization of Clad Steel Weld Zone with FCAW
}

\author{
Jaewon Park" and Chul-Ku Lee
}

(c) 2014 by KSPE and Springer

Retraction Note: Int. J. Precis. Eng. Manuf., Vol. 13, No. 12, pp. 2209-2214, 2012

DOI 10.1007/s12541-012-0293-y

The Editors of International Journal of Precision Engineering and Manufacturing (IJPEM) regret to report that this paper has been retracted due to duplication with the following paper published previously: Lee, J. H. and Park, J. W., A Study on the Mechanical Properties of Butt Welding Zone of Clad Steel According to the Process Design, Journal of the Korean Society Manufacturing Technology Engineers, Vol. 21, No. 4, pp. 532-540, 2012. IJPEM follows strict ethical standards and warrants the retraction of any paper that violates these standards. 